\title{
Dinâmicas urbanas endocoloniais: Luanda em Predadores, de Pepetela
}

\author{
Luca Fazzini*
}

\section{Notas sobre o colonial: a construção da cidade como espaço do im- político}

Em seu estudo sobre a Stasis, segundo capítulo da série Homo Sacer, o filosofo Giorgio Agamben (2015) argumenta como dentro do pensamento ocidental, a guerra civil poderia ser pensada enquanto paradigma político. $\mathrm{O}$ autor desdobra as suas reflexões a partir de dois lugares ou momentos arquétipos para refletir sobre a organização e as lógicas do poder: a polis grega, com os seus conflitos internos e discórdia entre famílias ou grupos étnicos (oikos), e a ademia, isto é, a ausência do povo, como elemento constitutivo do Estado Moderno, pensada através da análise do célebre frontispício da primeira edição do Leviathan (1651), de Thomas Hobbes. Servindo-se também de trechos de The elements of law (1640) e de De cive (1642) Agamben mostra como dentro da constituição do Estado Moderno, no ocidente, a soberania estaria nas mãos do povo (rex est populus) somente através de uma cisão necessária entre povo e multidão (dissoluta moltitudo), polo negativo na construção hobbesiana.

A pluralidade caraterística da multidão deveria ser ultrapassada, isto é, inibida em favor de uma única vontade capaz de engendrar uma ação unitária e de limitar a insegurança e a pluralidade. Como lembra Andrea Cavalletti em La città biopolitica: mitologie della sicurezza: "ponto de partida da construção hobbesiana é notoriamente o medo da morte violenta no estado de natureza. Objetivo final, alcançar a mais completa segurança, verdadeira condição de vida civil garantida pelo estado"1 (CAVAlletti, 2005, p. 54, tradução do autor). O povo, populus-rex- polo positivo na construção hobbesiana- deveria ser, portanto, unum quid, singular e homogêneo, pois a violência da guerra civil, da luta de todos contra todos, residiria justamente nas pulsões diferentes que habitam o corpo desunido da multidão.

\footnotetext{
Pesquisador de pós-doutorado na Universidade de São Paulo (USP), São Paulo, SP, Brasil. E-mail: lucafazz@hotmail.it.

1 Do original: "Punto di partenza della costruzione hobbesiana è notoriamente la paura della morte violenta nello stato di natura. Scopo finale, il raggiungimento della più completa sicurezza, vera condizione di vita civile garantita dallo stato" (CAVALLETTI, 2005, p. 54).
} 
Tendo em consideração a construção política do Estado Moderno discutida por Agamben a partir da teoria de Thomas Hobbes, a cidade colonial, com as suas tensões internas e práticas violentas, poderia igualmente ser pensada enquanto espaço paradigmático e metonímico, para refletir sobre a ação do poder. No interior dela, as dinâmicas discutidas pelo filosofo italiano - a ausência de povo, a aversão e o medo da pluralidade intrínseca à multidão - articulam-se às exigências constantes de acumulação do capital através da exploração do espaço e do corpo do $\mathrm{Ou}$ tro, práxis também constitutivas e intrínsecas à estruturação do Estado Moderno.

Olhando para o espaço urbano do "império português" na África, pode-se ver como a construção do espaço físico da cidade colonial, das normas e dos processos legais que regulamentam a vivência dos indivíduos que nela habitam, deu-se tendo como principal objetivo a dominação: "a cidade colonial construída numa perspectiva de dominação foi certamente o lugar da desigualdade, uma das estruturas mais repressivas, discriminatórias e eficazes do colonialismo europeu em África” (Henriques; Vieira, 2013, p. 7).

De acordo com os estudos de Fernandes (2012), Henriques (2004) e Domingos e Peralta (2013), as cidades implantadas por portugueses na África caracterizavamse pela centralidade de edifícios de caráter militar, situados quase sempre no litoral, que funcionavam como base de proteção seja para os pequenos povoados de colonos, seja para o porto, ponto nevrálgico na economia da cidade. Definidas por Nuno Domingos e Elsa Peralta como, fundamentalmente, "núcleos de trocas globais" (Domingos; Pereira, 2013, p. XVI), cidades como Luanda, fundada em 1576 pelo primeiro capitão donatário, e Benguela, que surgiu em 1617 "tiveram o tráfico transatlântico de escravos como principal atividade econômica até ao fim da primeira metade do século XIX, reconvertendo depois a sua atividade comercial na exportação das mercadorias "legítimas" [...], que alimentavam as economias europeias contribuindo para o desenvolvimento industrial" (HENRIQUes; VIEIRA, 2013, p. 15).

Se por um lado surgiram pelas mãos dos europeus acompanhando o processo de desenvolvimento daquilo que irá se impor como um verdadeiro mercado global, envolvendo as margens atlânticas de três continentes em fluxos que terão relevância essencial na demografia dos países envolvidos, por outro lado, a urbanização desses centros diferenciou-se dos da Europa. Enquanto na polis grega e na urbe romana, modelos clássicos de construção e organização dos territórios ocidentais, os espaços políticos e religiosos, muitas vezes coincidentes, ocupavam a área central, as cidades coloniais contavam com as instalações militares em suas centralidades. Por se tratar de territórios considerados hostis, a razão era obviamente defensiva, mas, ao mesmo tempo, também sintomática das estratégias de poder sobre os quais assenta a construção do espaço urbano colonial. Desde a sua formação, a cidade colonial constituiu-se como lugar do impolítico, como espaço de conflitos entre grupos diferentes. Os nativos e os estrangeiros, por sua vez divididos em etnias e classes também em conflito entre si. 
A cidade colonial nasce a partir do medo. Lida nos eixos políticos através dos quais Thomas Hobbes desenha o estado de natureza, na perspectiva ocidental, residem e convivem nela, constantemente, o medo da morte e o desejo de poder, "o perpétuo e incansável desejo de poder e mais poder que cessa apenas com a morte" (HobBes, 1991, p. 58). Tais afetos (medo e desejo), no entanto, não se resolvem na construção de uma sociedade civil, constituída por uma população homogênea, com o intuito de dissolver das massas o temor que as persegue no estado de natureza, como pretenderiam as narrativas ocidentais sobre a construção do Estado Moderno. A moltitudo dissolutionis ou moltitudo dissoluta, encarnação de violência e barbárie, os povos nativos ao longo da colonização foram sempre descritos como rebeldes, criminosos, ociosos, terroristas, não pode a priori constituir uma sociedade civil, isto é, ser inclusa dentro da norma preestabelecida a partir do modelo etnocêntrico ocidental. No espaço colonial, a diferença é entendida enquanto ontológica, como denuncia Frantz Fanon (1968).

Tal dinâmica é também funcional à práxis de exploração da riqueza e de construção e imposição de um modelo hegemônico que garanta a concentração e o perpetuar da mesma nas mãos de determinados atores. A razão europeia, através da ciência e da tecnologia, construiu um verdadeiro arsenal teórico e prático, "o controlo não apenas do espaço, mas do próprio corpo humano, dos comportamentos e das ações estava no centro da ação civilizadora. Tornar alguém civilizado significava libertá-lo de todas as formas de tirania: a tirania dos elementos da natureza sobre o ser humano, das doenças sobre a saúde, dos instintos sobre a razão, das superstições sobre a religião, da ignorância sobre o conhecimento científico e do despotismo sobre a liberdade" (MENESES, 2010, p. 73).

Se a primeira função da cidade colonial foi a de servir como posto comercial, também os seus sucessivos desenvolvimentos - principalmente a partir da segunda metade do século XIX, quando a ocupação da África se deu de forma mais abrangente- responderam às exigências econômicas dos países ocidentais, de acordo com a fase de desenvolvimento capitalista de cada contexto. Maria Paula Meneses sublinha como, de acordo com os documentos da época, a ação colonial de Portugal no continente africano respondia a duas necessidades contingentes: a de conter o crescimento da pobreza na metrópole e a de tornar produtivas e economicamente o mais rentável possível os espaços ultramarinos. O racismo colonial e o mito da superioridade branca, funcionais à lógica de acumulação do capital, como evidenciado por Étienne Balibar e Immanuel Wallerstein (1991), impuseram-se como dinâmicas centrais para alcançar os dois objetivos e foram construídos por uma série de processos jurídicos. Observando tais processos em perspectiva diacrônica, emerge de forma evidente a necessidade concreta de estruturar, na colónia, uma divisão entre o cidadão e a multidão sem direito, funci-

2 Do original: "the perpetual and restless desire of power after power, that ceases only in death" (HobBes, 1991, p. 58). 
onal para a expansão de uma força-trabalho barata, subjugada e dependente - as cidades coloniais deviam atender tal demanda.

Ao mesmo tempo que se fazia necessária a mão de obra que permitisse a extração dos recursos do território, mão de obra essa que não podia ser branca pois, segundo a mentalidade da época, aos portugueses não era recomendável o trabalho no calor de África (MENESES, 2010), impunha-se também a urgência de incluir - ou de mostrar que existisse a possibilidade da inclusão - parte da população nativa, de expandir o modelo ocidental. Isso era essencial para dois objetivos: aumentar a produção e criar uma suposta estabilidade social, pois incluir, embora de forma subalterna, os nativos dentro do modelo e do mapa cognitivo ocidental era visto como outra estratégia para vencer o medo e o terror das massas, juntamente à violência explícita e à força brutal da repressão. Obrigava-se desta forma aos africanos a inserção subalterna dentro das dinâmicas do capitalismo. Tanto o Regulamento do Trabalho Indígena de 1899 quanto o de 1914, publicados no Diário do Governo (n. 262, de 18 de novembro 1899; n. 237, de 25 de novembro 1914) sublinhavam a centralidade, dentro da ideologia colonial, do trabalho para os processos de "civilização":

O novo regulamento [o de 1899] consagrava a ideologia colonial, ao estabelecer no seu artigo I que todos os indígenas das províncias ultramarinas portuguesas estariam sujeitos à obrigação moral e legal de adquirir pelo trabalho os meios que lhes faltassem para substituir e melhorar a própria condição social, tendo plena liberdade de escolherem o modo de cumprir essa obrigação, o que, se não fosse feito, poderia ser-lhes imposto pelas autoridades. Este código, ao qual se seguiram outros, estabelecia que a obrigação do trabalho era vista como cumprida quando, a critério das autoridades locais, os indígenas provassem ter capital suficiente, ter produzido bens de exportação, ter cultivado terras por conta própria em quantidade e dimensão fixadas pela administração, ou o exercício de ofício ou profissão que lhes garantisse, a si e a seus familiares, níveis de vida compatíveis com os padrões civilizados (MenEses, 2010, p. 76).

O caráter arbitrário das medidas era evidente, assim como a disparidade de tratamento, com base na raça, entre os cidadãos nativos da metrópole e os da colónia, considerados, os últimos, como súbditos, obrigados através da coerção a respeitarem as imposições do poder. Antes dessas regulamentações acima mencionadas, o Regimento da Administração da fustiça nas Colóniais, publicado no Diário do Governo n. 43 em fevereiro 1894, tinha formalizado oficialmente, para os nativos, o trabalho obrigatório como pena.

A lógica de produção, funcional e necessária para as exigências da metrópole, foi certamente uma das causas dessa relevância dada ao trabalho na colónia. No entanto, na perspectiva ocidental e capitalista, como evidenciado por Max Weber em A ética protestante e o espírito do capitalismo (2001), a centralidade do trabalho não pode ser pensada apenas em termos de produção e de cálculos utilitaristas, 
pois ele implica uma série de normas e regras internas ao indivíduo que visam uma espécie de valorização ética do ato de cumprir deveres. Tal "internalização psíquica”, retomando a expressão usada por Safatle (2016, p. 166) ao discutir a perspectiva weberiana, funciona, de fato, como mecanismo de controle dos corpos, pois o trabalho "estaria organicamente vinculado às estruturas disciplinares de formação da natureza utilitária das relações próprias à individualidade liberal e seus direitos de propriedade, expressando apenas amplos processos de reificação" (SAFATLE, 2016, p. 162).

Mais do que em qualquer outro contexto, na colónia o trabalho foi usado propositadamente como ferramenta para o processo de alienação, de cisão e de autoestranhamento. Nos Manuscritos econômico-filosóficos (2004), Marx descreve a alienação do trabalhador dentro da sociedade capitalista a partir de quatro aspectos: na relação com o produto que apesar de ser fruto da sua força-trabalho não pertence ao trabalhador; na relação com a sua própria atividade dentro da qual ele é apenas um instrumento em mãos alheias; consigo próprio, em relação à sua própria essência (Wesen), por se ver privado do impulso criativo próprio ao humano; na relação com o outro, o capitalista, para o qual ele é apenas um meio, uma ferramenta para produzir mais-valia (MARX, 2004). Nos contextos coloniais, o trabalho forçado visa construir essa cisão no interior do colonizado, adquirindo assim as formas de um eterno purgatório dentro do qual o colonizado precisa passar para se expurgar de tudo aquilo que lhe é próprio, considerado selvagem e bárbaro, e, ao mesmo tempo, produzir aquilo que lhe é impróprio. Essa experiência se dá materialmente, sob a forma de extração de recursos que não lhe pertencem e produção de mais-valia, mas também ao nível imaterial, impondo-se um modus vivendi e uma hierarquia de valores exógena.

A inclusão dentro do universo capitalista e ocidental se dá, de fato, através de uma profunda exclusão, por processos de desfamiliarização dentro dos quais o trabalho corresponde apenas a uma parte. O "Estatuto Político, Civil e Criminal dos Indígenas das colónias portuguesas de África”, também conhecido como Estatuto do Indigenato, aprovado pelo Decreto n. 16.473 de 6 de fevereiro de 1929, com a criação da categoria jurídica dos chamados assimilados, oferece a medida concreta do estranhamento que os nativos tinham que sofrer para ser incluídos de forma subalterna dentro dos padrões impostos pelos portugueses:

Os assimilados - a terceira categoria presente no espaço colonial - encontram também expressão neste estatuto, que estipulava em detalhe as condições de acesso ao mesmo. Nos termos do Estatuto, assimilados eram os antigos indígenas que haviam adquirido a cidadania portuguesa, após provarem satisfazer cumulativamente os requisitos que transitavam do passado recente: a) ter mais de 18 anos; b) falar correctamente a língua portuguesa; c) exercer profissão, arte ou ofício de que aufira rendimento necessário para o sustento próprio e das pessoas de família a seu cargo, ou possuir bens suficientes para o mesmo fim; d) ter bom comportamento 
e ter adquirido a ilustração e os hábitos pressupostos para a integral aplicação do direito público e privado dos cidadãos portugueses; e) não ter sido notado como refractário ao serviço militar nem dado como desertor (artigo $5^{\circ}$ apud Meneses, 2010, p. 78).

As dinâmicas de criação da diferença por processos legais corresponderam, principalmente a partir da segunda metade do século XX, quando as colónias portuguesas na África passaram a receber um maior número de colonos vindos da metrópole, a uma série de planejamentos do espaço urbano, nunca ou quase nunca efetivados por completo, pelo menos em Angola, cujo intuito explícito era o de segregar e afastar a população nativa dos espaços destinados aos brancos. Criava-se então um espaço fragmentado, constituído por verdadeiros territórios de exceção destinados para toda aquela parte da população sem direitos de cidadania, sejam eles "indígenas" ou "assimilados". Uma parte da população que, na véspera da independência, incluía a grande maioria dos habitantes de Luanda: "no início dos anos 1970, somente 100.000 os 480.000 habitantes eram oficialmente reconhecidos como civilizados (INE, de acordo com o censo). Muitos eram os nativos provenientes de diferentes contextos - em um cenário urbano de enorme pobreza habitando nos musseques de Luanda, sobrevivendo pela economia informal paralela"3 (VIEGAS, 2012, p. 4).

Na cidade colonial são evidentes as tensões, dinâmicas e processos legais através dos quais se constituem os conflitos internos, base do pensar o político. Tais conflitos respondem aos objetivos concretos, ligados à acumulação da riqueza e à criação de uma estabilidade social - pensada a partir dos paradigmas políticos sobre os quais assenta a modernidade ocidental - funcional aos interesses econômicos de um determinado grupo: a elite econômica e financeira que, na colônia, corresponde por completo à elite europeia.

Contrariamente ao que pode ser pensado, do ponto de vista político, de organização e ação do poder sobre as massas, as independências não sancionaram a falência e a destruição de tais paradigmas. Pelo contrário, permitiram a persistência deles através da reorganização das dinâmicas internas necessárias para responder às exigências de autodeterminação e autoafirmação dos povos do continente. Movimento esse sublinhado, a partir de uma perspectiva filosófica, também por Achille Mbembe: "a crítica africana [...], sob o emblema da emancipação e da autonomia, ela aceitou, em sua maioria, as categorias básicas que o discurso ocidental usava, então, para seu relato da história universal” (MBEMBE, 2001, p. 180).

No seu ensaio As formas africanas de auto inscrição, o filósofo reconstrói os desdobramentos do pensamento africano sobre o continente à luz das continuida-

3 Do original: "in the beginning of the 1970 s only 100,000 of the 480 ,ooo inhabitants were officially ranked as civilized (INE, according to the census). Many were the natives from different backgrounds that - in a context of huge urban poverty - inhabited the musseques of Luanda, surviving on informal parallel economy" (VIEGAS, 2012, p. 4). 
des de alguns alicerces fundamentais do pensamento ocidental, tanto no essencialismo sobre o qual assenta aquilo que Mbembe chamou de "prosa do nativismo", como no que diz respeito à perspectiva nacionalista e marxista: "os nacionalismos africanos do pós-guerra, acompanhando, a este respeito, as tendências do seu tempo substituíram o conceito de "civilização" pelo de "progresso". Mas, eles assim o fizeram apenas para reforçar as teologias da época. Tendo posto de lado a possibilidade de uma reflexão propriamente filosófica sobre a condição africana, apenas a questão do poder permaneceu: quem podia capturá-lo e usufruí-lo foi legitimado" (MвEMBE, 2001, p. 181).

Tendo em consideração as dinâmicas do poder, desde os processos de legitimação até a ação e práxis cotidiana, o pós-independência evidencia a continuidade de determinados modelos assentes na invisibilização, marginalização e exploração daqueles corpos ainda construídos para serem Outros, em relação ao modelo dominante. Tal continuidade poderia, portanto, ser pensada enquanto ação ou domínio endocolonial contemporâneo, retomando a terminologia de Éric Alliez e Maurizio Lazzarato, nas suas reflexões sobre guerra e capital (2016).

A noção de endocolonialismo impõe-se assim como relevante para pensar as dinâmicas do poder dentro dos conflitos e das desigualdades permanentes na contemporaneidade. Se o colonialismo se constrói através de um movimento orientado para fora, que se desenvolve em processos de ocupação de territórios exteriores às metrópoles por parte de potências estrangeiras ocidentais, pela exportação e imposição violenta de um modelo cultural exógeno e pela negação e aniquilamento dos valores dos nativos que articula-se ao sistemático trabalho da morte, de destruição dos corpos, o prefixo "endo", do grego éndon ( dentro, para o interior, remete a uma série de significados aparentemente paradoxais quando conjugados com a palavra colonialismo, pois estaria apontando para uma dinâmica oposta à do colonial. Como substantivo masculino e neutro, o termo éndon refere-se respectivamente aos habitantes da casa e aos objetos do interior de uma casa. Como advérbio, a palavra grega pode ser traduzida como "dentro", "no interior de", comumente usada para se referir ao interior de uma casa ou da pátria. O endocolonialismo seria assim um colonialismo interno, que se efetiva dentro das fronteiras nacionais, sem prever a priori nenhum movimento voltado para fora.

No entanto, se considerarmos, de acordo com Antonio Negri e Michael Hardt (200o), que a instauração do modelo ocidental capitalista da sociedade de consumo alcançou uma escala mundial e que, com a exceção de alguns contextos particulares porém emblemáticos de ocupação militar contemporânea, como o caso da Palestina (МвемBE, 2016), a dominação sobre os Outros se dá principalmente por dinâmicas internas aos próprios países, através das armas fornecidas pela política, pela economia e pelo monopólio do uso da força. A noção de endocolonialismo ultrapassaria, então, o seu paradoxo etimológico ganhando, por sua vez, maior relevância. Se de um lado as tantas guerras de ocupação e conquista que marcaram a época colonial foram substituídas pela ação exploratória dos próprios governan- 
tes em favor do mercado - num continuum entre guerra, economia e política por outro lado, no interior de cada país, assiste-se à fragmentação da população e ao genocídio sistemático dos "indesejáveis" num jogo ininterrupto de inclusão subalterna e exclusão.

\section{Contemporaneidade urbana em Angola: Predadores, de Pepetela, e o domínio endocolonial}

A permanência das relações desiguais, moldadas sempre a partir da projeção de um poder hegemônico que erige constantemente "novas" subalternidades de acordo com os paradigmas excludentes que moldaram a modernidade colonial, pode ser observada no romance Predadores, de Pepetela. Romance que, ao ter como cenário Luanda, a capital do país, constrói um espaço urbano como palco de lutas e conflitos entre uma elite financeira em contínua ascensão econômica, e uma multidão entregue à exploração endocolonial e à arrogância da classe dominante.

A relevância da paisagem urbana luandense dentro da literatura angolana é algo que foi amplamente discutido pela crítica, pois além de ser Luanda "o local em que grande parte da literatura nacional é produzida, lançada e comentada" (MACÊDO, 2008, p. 14), a cidade serviu frequentemente de metonímia para pensar e discutir a história e a realidade do país. Movimento que envolveu também o próprio $\mathrm{Pe}-$ petela em diversas obras, pois, como lembra Inocência Mata, a interligação entre a história e a literatura sempre marcaram a escrita de um literato que, "sociólogo por formação e historiador por vocação, quando a história se cala no autor, ele recorre à ficção. Ou como diz o próprio Pepetela, a história ajuda a enquadrar a questão da construção da nação e do estado-nação" (MATA, 2001, p. 138).

A história recente do país e a realidade social angolana também habitam as páginas de Predadores, romance no qual Pepetela encena os conflitos subjacentes à emergência de certa elite econômica luandense e que abraça um período temporal que vai de 1974 até 2002, atravessando desta forma as fases fulcrais da política e da história recente do país. De fato, o plano de fundo é constituído pelas transições vividas por Angola durante 30 anos, período marcado por mudanças radicais na política e na economia. Dentro dessas, destaca-se sem dúvida a independência, que funciona como ponto de partida cronológico para o romance, e a transição de República Popular para Democracia Multipartidária, em 1991, com as primeiras eleições de 1992 que, por sua vez, funcionam de incipit para Predadores:

O homem de impecável fato azul, que passaremos a chamar Vladimiro Caposso, rodou cuidadosamente a chave na fechadura do apartamento, de modo a não fazer barulho. Mal abriu a porta, ouviu os gemidos de Maria Madalena, a grande cabra, e os urros de gozo do dito Toninho. [...] Na rua acontecia uma passeata política, com muitos carros cheios de gente agitando bandeiras rubronegras, cartazes, jovens de camisolas vermelhas e punhos erguidos, gritando slogans e canções políticas. Faltava uma semana para as eleições (PePEtela, 2012, p. 9). 
No que diz respeito ao plano econômico, de acordo com os estudos de José Mena Abrantes (2005), José Manuel Alves da Rocha (2009), Alcides Goularti Filho e Avelino Euclides da Silva Chimbulo (2014), deve ser sublinhada a passagem do chamado Modelo Socialista de Economia Centralmente Planejada (1975/1988), para a economia de mercado, em 1989, e depois de novo para uma política econômica intervencionista chamada de Crescimento Acelerado, em 2002. Essas fases foram marcadas mais pela continuidade das dinâmicas de exploração do território perpetradas pela elite financeira do que por rupturas substanciais. De fato, em um país que tem nos hidrocarbonetos um dos seus maiores recursos, já durante a fase socialista, de controle centralizado, existia um enclave autônomo, capitalista, localizada na região de Cabinda. Um enclave cuja relevância no panorama político e econômico nacional era sem dúvida central:

Angola passou também a contar com a cooperação de outros países socialistas especificamente aqueles do Leste Europeu, além de Cuba e até do Vietnã. Estavam então lançadas as bases para o modelo de economia centralmente planejada, contudo, existia uma particularidade no "modelo socialista angolano": um "enclave petrolífero capitalista” na província de Cabinda, localizada ao norte de Angola. Embora os dirigentes de Angola tenham assumido que eram um país socialista, a dependência em relação ao capital estrangeiro e a necessidade de um grande volume de recursos para financiar a organização inicial do novo país permitiam a convivência com esse pequeno "enclave”. Este "enclave do petróleo”, na época da independência, já assumia um papel fundamental na geração de finanças para Angola (Filho; Chimbulo, 2014, p. 93).

Em 1988, com a transição de Angola para a economia de mercado, o Fundo Monetário Internacional "por intermédio dos seus técnicos, rapidamente passou a impor as medidas do Consenso [de Washington]" (Filho; Chimbulo, 2014, p. 95). Desconsiderando o fato de um país como Angola, que sofreu a exploração colonial, as violências da luta armada contra o colonialismo, e na época ainda envolvido em uma desgastante guerra civil, não ter uma base econômica e legal minimamente adequada ao sistema capitalista (RochA, 2009).

Como afirmam Antonio Negri e Michael Hardt, "as lutas de libertação achavamse "vitoriosas" mas, apesar disso, consignatas a uma área do mercado global, um vasto gueto com fronteiras indeterminadas (Negri; HARDt, 200o, p. 273). Assim, em Angola a violência endocolonial perpetrada por parte da elite financeira local, conjugou-se aos interesses neocoloniais ou imperialistas, retomando, com esse termo, aquilo que segundo Lenin (2002) seria uma das caraterísticas centrais do desenvolvimento do capitalismo financeiro de Washington.

No romance, Pepetela acompanha as transformações de Angola até 2002, ano em que se encerra Predadores e que corresponde tanto ao fim da guerra civil começada em 1975, quanto, no plano econômico, à volta das políticas intervencionistas do Estado, acontecimentos claramente interligados: 
Quando aos 22 de fevereiro de 2002 foi confirmada oficialmente a morte do então líder do partido opositor ao governo, a Unita, um dos principais responsáveis pela guerra civil que desestabilizou Angola, abriam-se as perspectivas para melhorias e avanços substanciais na economia angolana. [...] Se a paz tanto almejada havia sido alcançada, tudo indicava que, justamente em função das mazelas deixadas pela guerra, o governo angolano teria muito o que fazer para reerguer a economia. O mercado por si só não tinha as condições adequadas para a promoção do crescimento econômico, e assim, cabia ao Estado, por intermédio de intervenção na economia com política econômica intervencionista, revitalizar a economia (Filho; Chimbulo, 2014, p. 98).

Apesar das tantas transformações atravessadas pela recém-independente Angola em pouco menos de trinta anos, em Predadores Pepetela consegue envolver o leitor em um eterno e imutável presente, marcado pela repetição e persistência das mesmas lógicas predatórias apoiadas, ora pelo partido, ora pelo mercado, de acordo com as fases políticas atravessadas pelo país. A organização fragmentada e cronologicamente irregular dos capítulos funciona como estratégia para transmitir essa condição de imutabilidade, sem, no entanto, desnortear o leitor, auxiliado pela informação temporal específica (mês e ano) através da qual o autor introduz cada capítulo.

Acompanhando a trajetória pessoal de Vladimiro Caposso, protagonista do romance, assiste-se à consolidação no tecido urbano luandense, de uma elite econômica burguesa, moldada pelo padrão ocidental da sociedade de consumo, cujo único objetivo é explorar o território e levar o capital financeiro para fora do país. Por esse ângulo, a passagem de propriedade entre o comerciante português Sô Amilcar, que retorna para Portugal após a independência, e um Caposso recémchegado em Luanda, novo dono da casa e da pequena loja que tinha sido de Sô Amilcar, pode assim ser lida como uma metáfora da passagem do colonialismo ao endocolonialismo, ou colonialismo interno. Do colono que, após a independência de Angola, deixa os seus negócios e as suas antigas propriedades nas mãos daqueles indivíduos que irão se tornar os novos donos do país:

Caposso entrou em casa como proprietário. Pela primeira vez na vida. Todas as casas onde vivera com o pai eram alugadas, nunca lhes pertenceram. Esta sim, era dele, mesmo se a meias, pois ainda era sócio. Entrou muito toldado pelo álcool, mas uma ideia fez aclarar subitamente a cabeça. Se sô Amílcar não voltasse, ele era dono de tudo. Sentou num saco de fubá, batendo nele como se de um cavalo se tratasse. O branco não tinha intenção ou esperança de voltar, era evidente. [...] E havia mais: sô Amílcar lhe explicara, a casa estava isolada num terreno pequeno, mas que também lhe pertencia, tinha registado o terreno adjacente na esperança de um dia poder alargar a loja com os lucros e fazer dela um verdadeiro negócio, sonhos irrealizados. Caposso podia, portanto, crescer, a parte vaga do terreno era quatro vezes a construída. Tinha de reforçar 
as marcas, limitando a propriedade [...]. Um dia podia construir uma verdadeira mansão ali, num bairro que não era nobre mas também não era musseque (PePetela, 2012, p. 86-87).

Tal passagem, simbólica, corresponde de fato à figura do empresário Vladimiro Caposso que, de forma ambígua, reproduz no dia a dia urbano os mesmos paradigmas e a mesma visão de mundo - até nos próprios preconceitos - que acompanharam a chegada e a permanência dos europeus na África. No seu desprezo pelas classes populares, pelos trabalhadores, pelos moradores dos musseques de Luanda e pelas populações do interior do país, da área rural, vislumbram-se a mesma visão degradada que parte da tradição filosófica ocidental projetou sobre a multidão. A essas perspectivas correspondem, também, atitudes e gestos que deixam transparecer a construção por parte de Pepetela de uma personagem totalmente moldada por certa "ética" burguesa e capitalista: ao individualismo exacerbado, conjugam-se uma práxis predatória nos negócios e relações de poder autoritárias dentro dos circuitos afetivos, com a mulher e com os filhos.

Acumulação de riqueza a qualquer custo e conquista de certo status são, de fato, incentivos para as ações de Caposso ao longo de todo o romance. Assim, a euforia por ter herdado as propriedades que tinham sido antigamente do português Sô Amilcar, substituiu-se logo depois pela necessidade de abandonar tudo o quanto mais cedo. À medida que proliferavam os negócios, impunha-se de forma sempre mais urgente o dever de mudar de endereço, pois a atual residência abrigava em si um "pecado original", ou seja, a localização em uma área pobre da cidade:

Apartamento não queria, nem morto, isso de ter vizinhos por baixo ou por cima era coisa de europeu e pobre. A casa do Marçal, apesar dos acrescentos e algumas melhorias feitas, já não lhe servia. Até tinha terreno para a aumentar, também podia pôr pisos em cima, embelezar. Mas não corrigiria o pecado original da casa, estar situada no pobre Marçal, bairro prefigurando o musseque onde se acumulavam os excluídos da cidade. Tinha de se mudar para uma vivenda do Alvalade, bairro fino, o último bairro rico a ser criado pelos colonos e agora a residência da maior parte da gente importante da terra. Como podia, ao pretender fazer um negócio de relevo, dar o endereço do Marçal, alguém o levaria a sério? (Pepetela, 2012, p. 345).

A escolha do bairro do Marçal para abrigar primeiramente a loja do português Sô Amilcar e depois a residência de Caposso não é casual e deixa transparecer a familiaridade do autor com a história e a geografia social de Luanda. De fato, como sublinhado por Fernando Augusto Albuquerque Mourão em Continuidades e Descontinuidades de um processo colonial através de uma leitura de Luanda: uma interpretação de desenho urbano (2006), Marçal é um dos musseques mais antigos da cidade de Luanda, pois foi criado ainda na época colonial, como os de Mota e Sambizanga, e hospedou um número significativo de portugueses pobres. 
De fato, Marçal surgiu como um bairro popular durante a ocupação portuguesa. Construído através da parceria público-privada e tendo por modelo a township sul-africana, destinava-se aos trabalhadores de baixa renda, sejam eles africanos ou portugueses. A proximidade do bairro com os pontos nevrálgicos da cidade fez com que ele sofresse um aumento demográfico significativo, ao ponto de torná-lo similar aos musseques informais, dos quais se diferencia ainda por ter um índice de pobreza menor e um melhor acesso aos serviços de transportes coletivos. As intervenções urbanas na cidade de Luanda efetivadas, seja durante a época colonial seja no pós-independência, quase exclusivamente através de uma nefasta parceria público-privada, são exemplos concretos das continuidades e das persistências dos paradigmas coloniais na contemporaneidade, pois vieram reforçar tanto a fragmentação hierárquica do espaço urbano quanto a segregação dos considerados "indesejados". De acordo com os dados apresentados por Sílvia Leira Viegas no seu artigo Urbanization in Luanda, se em 1970 a população branca na cidade, em sua maioria moradora do "asfalto", alcançava $26 \%$, hoje em dia, cerca de $80 \%$ da população luandense reside entre os chamados "bairros populares" e os diferentes tipos de musseques (VIEGAS, 2012), mantendo-se, portanto, praticamente inalterada a proporção entre os moradores das áreas mais abastecidas da cidade e as mais carentes.

Se, por um lado, os espaços antigamente destinados ao colonizador foram rapidamente apropriados pela nova elite local que, tomando como modelo o condomínio fechado brasileiro, está a expandir a construção da "cidade formal" em áreas de nova ou mais recente urbanização, por outro lado, os musseques mais distantes sobrevivem no completo esquecimento do poder público e os da zona central da cidade sofrem um rápido processo de gentrificação e numerosas desapropriações. É o caso, entre outros, do Catambor, musseque da área central de Luanda, que aparece em Predadores por ser local de residência de Nacib, jovem de origem popular, apaixonado por Mireille - filha mais nova de Caposso - figura central na economia do romance:

Nacib Germano de Castro desceu a rua principal do Alvalade, a caminho do seu bairro miserável, o Catambor. Tinha nascido na altura em que a televisão angolana transmitia pela primeira vez uma telenovela, "Gabriela”, baseada num livro famoso do não menos eminente escritor brasileiro Jorge Amado. [...] Por causa do carinho dispensado à obra, estava combinado há muito na família: se nascesse menina, se chamaria Gabriela. Nasceu rapaz, ficou Nacib, podia ser de outra maneira? (PePetela, 2012, p. 29).

Os trânsitos constantes de Nacib entre Catambor e o bairro "nobre" do Alvalade, para onde se muda a família Caposso após deixar a casa do Marçal, são significativos para pensar tanto a construção da figura de Nacib, quanto a estigmatização e marginalização dos musseques e da população que neles reside. Apesar de ser um romance que tem seu foco nos modos e costumes que caracterizam a 
elite econômica luandense, o multiperspectivismo que caracteriza a escrita de $\mathrm{Pe}$ petela (MATA, 2001, 2012) pode ser observado, em Predadores, naquela galeria de figuras através da qual o autor desenha o panorama humano de Luanda e graças à qual se vislumbra toda uma série de figuras da exclusão que permitem detectar, ainda uma vez, a persistência dos paradigmas coloniais.

Nesse sentido, Nacib aparece como uma figura emblemática. Criado dentro de uma das tantas redes de reciprocidade que ultrapassam os laços familiares típicos das realidades dos musseques de Luanda, Nacib é uma personagem sempre em trânsito entre dois universos antagônicos: o próprio musseque e o asfalto, onde constrói parte dos seus sonhos, cursando a faculdade de engenharia e cultivando o amor adolescente por Mireille. A Luanda vista pelos olhos de Nacib é uma cidade outra, em relação à vivenciada por Vladimiro Caposso. Se a cidade do empresário está marcada por relações endocoloniais, hierárquicas e de exploração, a de Nacib deixa transparecer a existência de redes de solidariedade e de reciprocidade que permitem atenuar a carência e a falta de estruturas: "as cidades em África são, desde a sua origem, ponto de contacto entre duas sociedades estranhas uma à outra: uma, caracterizada pelo individualismo dando primazia aos bens materiais e outra dando prioridade ao espírito comunitário, ao peso da "tradição", à solidariedade da linhagem, do clã, do grupo étnico. Nasce, com este contacto, uma civilização de natureza ambígua" (RoDRIGUEs, 2003, p. 8).

De acordo com Cristina Udelsmann Rodrigues em Recomposição social e urbanização em Luanda (2003), as redes de solidariedade nas comunidades periféricas da capital angolana estabelecem-se tendo como base principalmente a família no sentido mais amplo do termo, envolvendo não apenas a consanguinidade, mas também algumas formas de atribuição voluntária de relações de tipo parentesco. Ao lado desses laços familiares, vizinhança, religião e trabalho também oferecem suportes para a constituição dessas redes, necessárias, pois além do descaso do poder público em relação às áreas mais carentes da cidade, grande parte da população da capital angolana encontra-se deslocada em Luanda, constituída pelas rotas de enormes fluxos migratórios.

A construção do espaço e da vivência nos musseques por parte de Pepetela em Predadores aparece então marcada pela heterogeneidade dos seus habitantes e pela relevância das dinâmicas de reciprocidade e de solidariedade através das quais as populações economicamente mais vulneráveis sobrevivem em um contexto hostil, fortemente marcado por mecanismos predatórios de exploração endocolonial. É a partir da solidariedade que, no romance, se constrói a amizade entre Nacib e Kesseke, um jovem morador de rua que tinha chegado a Luanda sozinho após a morte do pai, vindo de Benguela, e que pouco a pouco foi aceito dentro da família:

Dona Celestina das Dores a princípio não gostou nada da ideia do filho. Se abrissem a casa a todas as crianças que dormiam na Marien Ngouabi, só para falar de uma rua de Luanda, estavam mal [...]. Todas as semanas 
o rapaz vinha tomar banho a casa e lavar a roupa no tanque existente no quintal. Claro, para Kasseke, aquela casa pobre de um musseque pobre era um palácio, todos dormiam até em colchões de esponja embora fina sobre catres feitos pelo próprio Bernardo Domingos, uns verdadeiros nababos. Celestina mais tarde alargou a permissão a Manuel, tudo por causa das boas maneiras de Kasseke. E às vezes até lhes dava alguma coisa para comerem pois sabia, a venda de produtos nas ruas não servia para mais que uns bocados de pão com chouriço ou barrados de goiabada, comprados nas zungueiras (PePetela, 2012, p. 244).

Como Kasseke e como a maioria da atual população da capital, também o próprio Vladimiro Caposso havia chegado em Luanda anos antes, em 1974, quando ainda tinha o nome de João - emigrando de uma região ao sul da capital, conhecida como Cuanza-Sul. No entanto, de acordo com a situação política da época e visando a obtenção de algum tipo de privilégio pessoal, o recém-chegado optou por reconfigurar a sua própria identidade. O nome de João, demasiado português para um contexto ainda fortemente marcado pela luta anticolonial, foi então substituído por Vladimiro, "adaptação portuguesa de Vladimir Ilitch Lenine, pois claro" (Pepetela, 2012, 59), na tentativa de construir para si próprio uma identidade adequada às tendências socialistas e às influências soviéticas que dominaram o discurso político angolano após a independência. A mudança no lugar de nascimento, de Calulu, no Cuanza-sul, para a comuna de Catete, na província de Luanda, respondia à mesma lógica: espaço ligado à luta anticolonial podia oferecer para Caposso a inserção em uma das redes de solidariedade acima mencionadas.

Com o cartão do MPLA na mão obteve um dos novos bilhetes de identidade, quando era tudo fácil [...]. Calulo, a terra onde nasceu no CuanzaSul, não lhe pareceu granjear muito prestígio. O que estava a dar era Catete, terra do primeiro Presidente da República, do maior Herói da luta, Hoji y a Henda, e de alguns responsáveis importantes. A terra onde se nasce pode suscitar solidariedades e apoios, já se sabe. Não há nada melhor do que chegar ao pé de um muata e dizer o meu pai manda os cumprimentos, sou fulano de tal, da família tal, morávamos mesmo perto da casa da sua família, o que provoca um sorriso cúmplice e, se possível, uma decisão positiva num requerimento ou uma nomeação surpreendente. Mesmo se a vizinhança nunca tivesse existido. Sempre foi assim e em todo o lado, não venham cá dizer que só nós inventámos o compadrio, o aldeanismo ou sanzalismo, como quiserem chamar essas práticas (Pepetela, 2012, p. 50-51).

No entanto, se essas alterações na identidade planejadas por Caposso conseguiram propiciar-lhe alguns proveitos relevantes na época pós-independência, como ele mesmo afirmará, também lhe trouxeram, nos anos seguintes, inúmeros problemas, à medida em que as roturas auspicadas pela luta anticolonial iam abrindo espaço para os processos de legitimação do poder instituído após as independências. A Luanda encenada por Pepetela em Predadores é, de fato, uma cidade em 
rapidíssima mudança e transformação. Uma metrópole entregue ao capital financeiro que precisa esquecer o mais rápido possível o passado socialista que sustentou parte da luta anticolonial. Um lugar onde não há espaço para memórias que se tornaram incômodas perante as novas conjunturas econômico-políticas e perante os olhos de uma elite financeira exclusivamente interessada na extração das suas riquezas, para depois transferi-las para fora do país, num movimento muito próximo ao que marcou a época colonial.

Assim, a figura de Simão Kapiangala, morador de rua atropelado pelo jipe de Vladimiro Caposso conduzido pelo filho Ivan, impõe-se como fortemente simbólica. Natural do Bié, além de ser mais um indivíduo deslocado, Kapiangala foi um ex-militar e um mutilado de guerra que perdeu ambas as pernas por causa de uma mina hibernada, pisada durante um treino. Kipalanga "lutou contra tudo o que lhe apareceu pela frente, sobretudo os sulo-africães, como chamava aos racistas do apartheid. Chegou mesmo a distinguir-se nos combates precedendo o acordo de Lusaka" (PePETEla, 2012, p. 157).

Depois de médicos cubanos terem-lhe salvado a vida, Simão Kipalanga viuse obrigado a morar na rua, pois o Estado, ocupado em propiciar ou facilitar os negócios particulares de poucos, não conseguiu fornecer ao ex-militar próteses para as pernas, nem uma pensão mínima que lhe garantisse sobreviver naquelas condições precárias:

Simão Kapiangala nem cão era para a maior parte dos que passavam ali. Para um cão olha-se, pode se pensar é um rafeiro cheio de sarna, mas vêse, faz-se notar, ao passo que com ele as pessoas passavam pressentindo a presença e incomodados por ela, desviando logo a vista para o lado, fazendo esforço para não terem visto. Nunca o confessarão, nem no mais escondido dos seus segredos, mas para uns tantos apressados de acumular dinheiro estilando nos carros de última geração mais caros do mundo, aquela metade de homem era incómoda ali no meio da rua, pois mesmo em silêncio gritava acusações que eles não gostavam de recordar, rastarranha rastavurra rastaparta (PEPETELA, 2012, p. 166).

Neste sentido, a figura de Simão Kipalanga bem representa as dinâmicas excludentes do poder sobre os corpos, em particular sobre os que se encontram nas situações mais vulneráveis, dinâmicas essas que não são apenas angolanas, mas que encontram processos convergentes em vários outros contextos: quando um indivíduo não serve mais, não é mais rendável dentro da lógica de produção ou das dinâmicas de consumo caraterísticas das sociedades capitalistas, este passa a ser matável, ou então passa a viver como em um estado de morte em vida:

Por vezes alguém lembrava, Luanda deve ser uma cidade bonita, não pode apresentar lixo nas ruas. E vinham polícias militares, apanhavam-no e aos outros mutilados que proliferavam nas ruas da cidade, os levavam como 
lixo para umas barracas longe do centro, onde davam rações de combate para comerem durante dois dias e depois os esqueciam para morrerem mais depressa. Os que tinham próteses ou só tinham perdido uma perna eram os primeiros a chegar de novo às ruas de Luanda. Simão, se enrolando para rebolar sobre o asfalto incandescente, demorava mais, muito mais, era sempre o último a chegar ao sítio do emprego, como dizia. Alguém imagina que uma pessoa se possa locomover tendo só um braço? (Pepetela, 2012, p. 161).

Em Predadores, é justamente através dessas figuras simbólicas e dos seus trânsitos urbanos que Pepetela encena as tensões e as violências internas que marcam a atuação do poder e o domínio endocolonial sobre os corpos e o território. Assim, se através do protagonista, Vladimiro Caposso, acompanhamos a Luanda do poder financeiro, da exploração endocolonial do território e da visão degradada dos Outros que compõem a multidão heterogênea e plural, graças à figura de $\mathrm{Na}$ cib, Pepetela consegue reproduzir no romance as dinâmicas do cotidiano urbano sobre as quais assentam a vivência da Luanda que não sonha apenas em dólares. Ao mesmo tempo, com Simão Kipalanga, o autor chama a atenção sobre a memória da guerra de libertação e sobre todos aqueles restos humanos que, no esquecimento geral e na invisibilidade perante os olhos de muitos, são mortos ou deixados morrer pelo poder. Resíduos que o sistema capitalista, subjacente ao domínio e a exploração endocolonial do território e dos corpos, não para de produzir.

\section{Referências}

Abrantes, José Mena. A paz em Angola. In: Abrantes, José Mena (Org.). Angola em paz: novos desafios. Luanda: Edições Maianga, 2005.

Agamben, Giorgio. Stasis. Torino: Bollati Boringhieri, 2015.

Alliez, Éric. Lazzarato, Maurizio. Guerres et capital. Paris: Éditions Amsterdam, 2016.

Balibar, Étienne; Wallerstein, Immanuel. Race, Nation and Class: Ambiguous Identities. London/New York: Verso, 1991.

CAVAllettr, Andrea. La città biopolitica: mitologie della sicurezza. Milano: Mondadori, 2005.

Domingos, Nuno; Pereira, Elsa. (Orgs.). Cidade e império: dinâmicas coloniais e reconfigurações pós-coloniais. Lisboa: Edições 70, 2013.

Fanon, Frantz. Os condenados da terra. Rio de Janeiro: Civilização Brasileira, 1968.

Fernandes, José Manuel. Arquitectura e urbanismo na África Subsaariana: uma leitura. In: MAtтoso, José (Org.). Património de origem portuguesa no mundo, África, Mar Vermelho, Golfo Pérsico. Lisboa: Fundação Gulbenkian, 2012, p. 204-216. 
Filho, Alcides Goularti; Chimbulo, Avelino Euclides da Silva. Política econômica de Angola de 1975 a 2012: a trajetória da mudança de modelos. RDE-Revista de desenvolvimento econômico, Salvador, n. 29, dez., p. 92-104, 2014.

Henriques, Isabel Castro. Território e identidade. A construção do Angola colonial (c. 1872- c. 1926). Lisboa: Centro de história da universidade de Lisboa, 2004.

Henrigues, Isabel Castro; Vieira, Miguel Pais. Cidades em Angola: construções coloniais e reinvenções africanas. In: Domingos, Nuno; Pereira, Elsa. (Orgs.). Cidade e império: dinâmicas coloniais e reconfigurações pós-coloniais. Lisboa: Edições 7o, 2013. p. 7-59.

HobBes, Thomas. Leviathan. Cambridge/New York: Cambridge University Press, 1991.

Lenin, Vladimir I.. L’impérialisme, stade suprême du capitalisme. Montreuil-sousBois: Science Marxiste, 2005.

MACÊDo, Tania. Luanda, cidade e literatura. São Paulo: Editora UNESP, 2008.

Marx, Karl. Manuscritos econômico-filosóficos. Trad. J. Ranieri. São Paulo: Boitempo, 2004.

MATA, Inocência. Pepetela e as (novas) margens da "nação" angolana. Veredas. Revista da associação internacional de lusitanistas, Porto, n.4, p. 133-145, 2001.

MATA, Inocência. Ficção e história na Literatura Angolana: o caso de Pepetela. Lisboa: Edições Colibri, 2012.

Mвемве, Achille. As formas africanas de auto-inscrição. Estudos Afro-Asiáticos, Ano 23, n. 1, p. 171-209, 2001.

Mвеmbe, Achille. Necropolítica. Arte \& Ensino. Rio de Janeiro, n. 23, 2016. p. 123151.

Meneses, Maria Paula G. O 'indigena' africano e o colono 'europeu': a construção da diferença por processos legais. E-Cadernos CES, Coimbra, n.7, p. 68-93, 2010.

Mourão, Fernando Augusto Albuquerque. Continuidades e descontinuidades de um processo colonial através de uma leitura de Luanda: uma interpretação do desenho urbano. São Paulo: Terceira margem, 2006.

Negri, Antonio; Hardt, Michael. Império. Trad. Berilo Varga. $3^{\text {a }}$ Ed. Rio de Janeiro/São Paulo: Record, 2000.

Pepetela. Predadores. 8a Ed. Alfragide: Edições Dom Quixote, 2012.

Rocha, José Manuel Alves da. Os limites do crescimento econômico em Angola: as fronteiras entre o possível e o desejável. Luanda: Editora Nzila, 2009.

Rodrigues, Cristina Udelsmann. Recomposição social e urbanização em Luanda. Centro de estudos africanos, Lisboa, p. 1-26, 2003. 
SAfatle, Vladimir. O circuito dos afetos: corpos políticos e o fim do indivíduo. Belo Horizonte: Autêntica Editora, 2016.

VIEgAS, Sílvia Leiria. Urbanization in Luanda: geopolitical framework. In: International planning history society (IPHS) Conference, São Paulo: FAUUSP, 2012. p. $1-20$.

Weber, Max. A ética protestante e o espírito do capitalismo. Trad. José Marcos Mariani de Macedo. São Paulo: Companhia das Letras, 2001.

Recebido em 20 de setembro de 2020.

Aprovado em 8 de abril de 2021.

\section{Resumo}

Dinâmicas urbanas endocoloniais: Luanda em Predadores, de Pepetela

\section{Luca Fazzini}

Em Predadores, romance publicado em 2005, o escritor Pepetela, ao encenar as práticas cotidianas da elite financeira angolana, propõe uma reflexão sobre o pósindependência do país destacando as continuidades das dinâmicas do poder, apesar das mudanças radicais que Angola sofreu nas últimas décadas, tanto no plano político como no econômico. Através da leitura crítica do romance mencionado e de uma mais ampla discussão sobre a construção ocidental do espaço colonial como espaço do impolítico, estritamente vinculado às demandas do capital, o presente artigo pretende investigar as continuidades na organização e nas práticas do poder na cidade de Luanda, destacando a persistência das lógicas coloniais no pós-independência. Tais persistências e continuidades, conjugadas à ação transnacional do capital, tornariam adequada a noção de endocolonialismo, para pensar a organização do poder na contemporaneidade angolana.

Palavras-chave: estudos pós-coloniais, endocolonialismo, literatura angolana. 